\title{
Undersurface of the Frontal Lobe
}

National Cancer Institute

\section{Source}

National Cancer Institute. Undersurface of the Frontal Lobe. NCI Thesaurus. Code C33832.

The inferior orbital portion of the prefrontal cortex that is concave and rests on the orbital plate of the frontal bone; it is divided into four gyri by a well-marked, $\mathrm{H}$-shaped orbital sulcus: the medial, the anterior, the lateral, and the posterior orbital gyri. 